ENSAIO FOTOGRÁFICO 



\title{
ARTE PARÁ EM FOTOS, 2012 A 2015
}

\author{
John Fletcher (D) $\triangle$
}





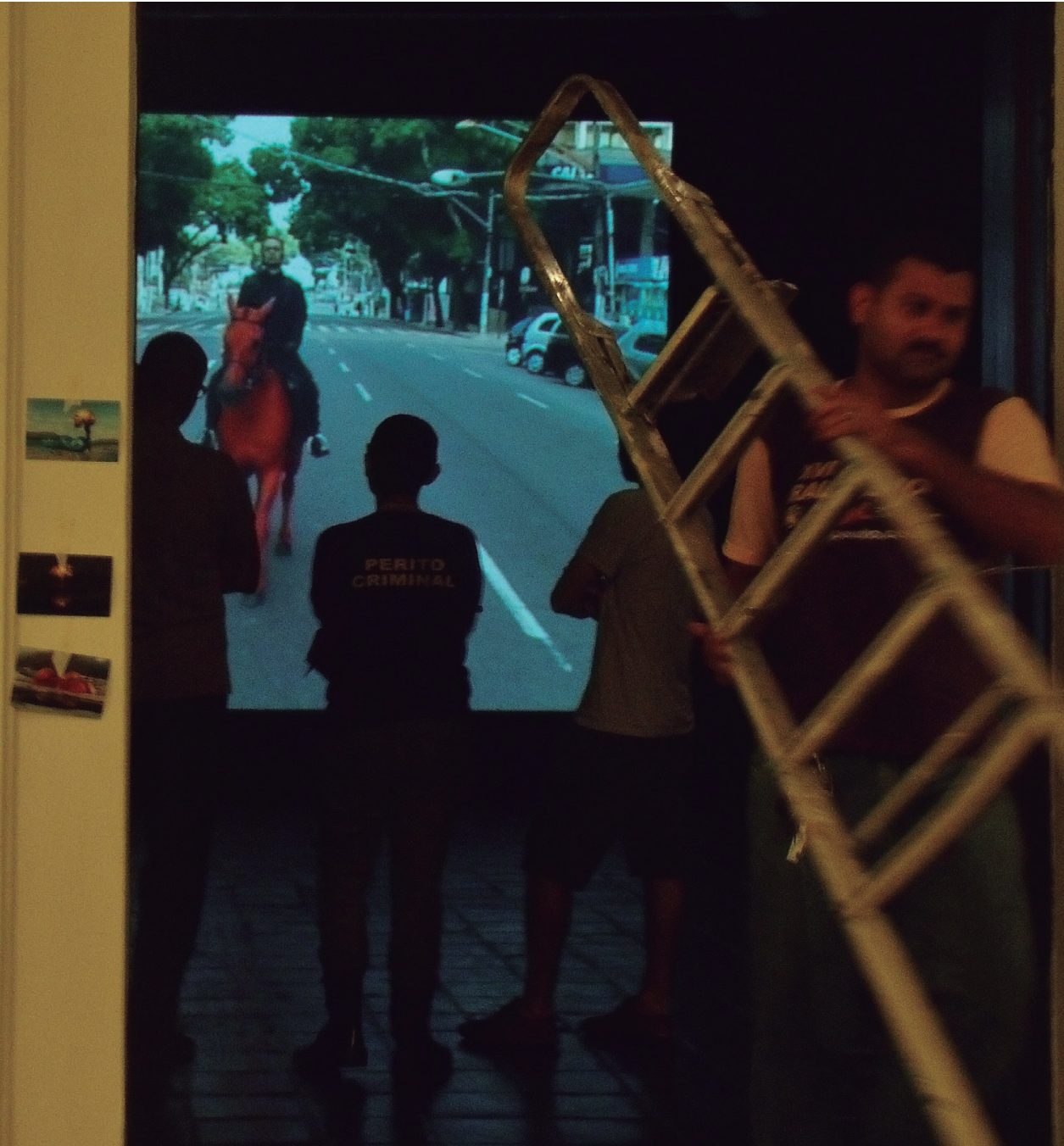

Figura 1 - Arte Pará 2012. 

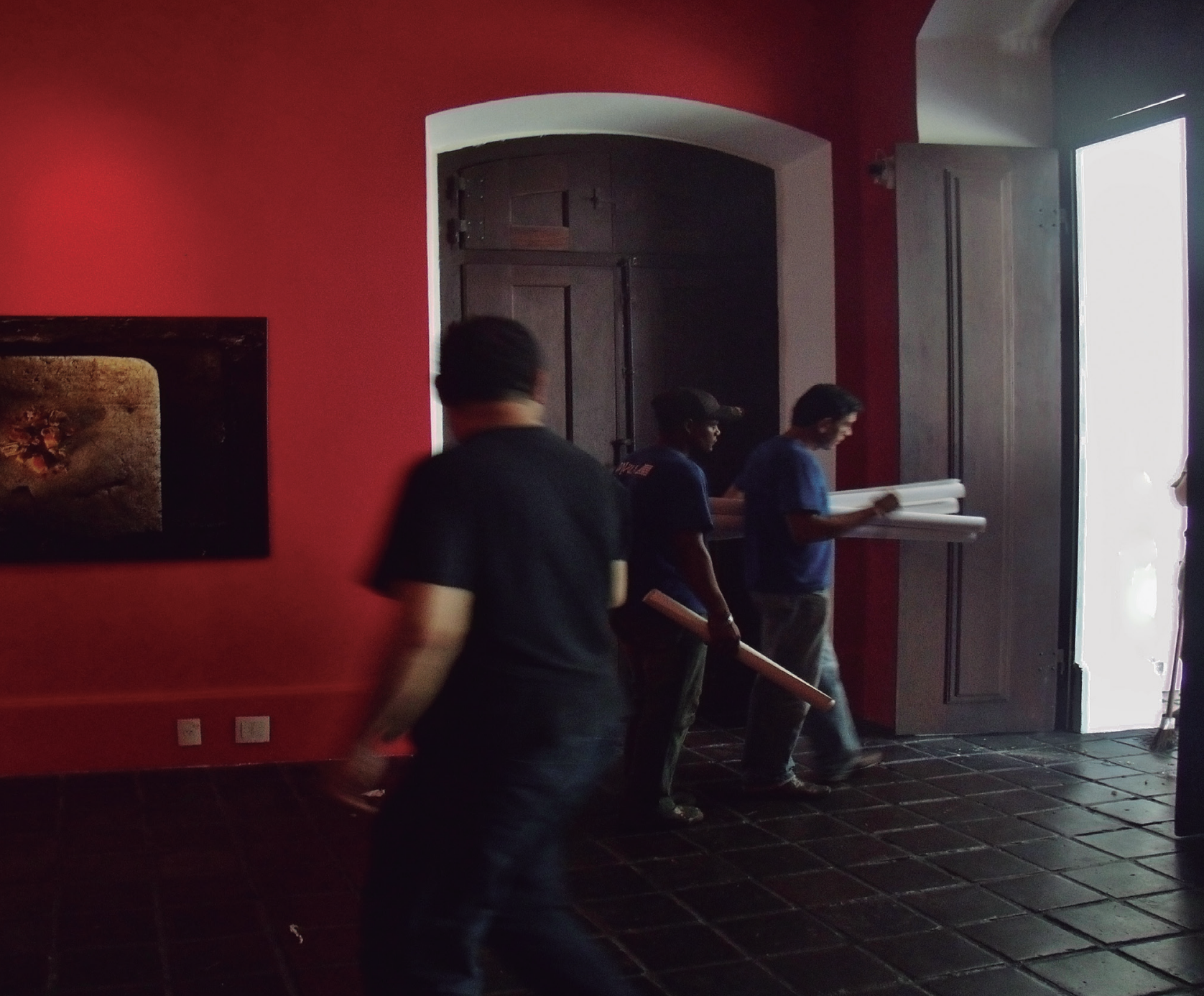

Figura 2 - Arte Pará 2012. 

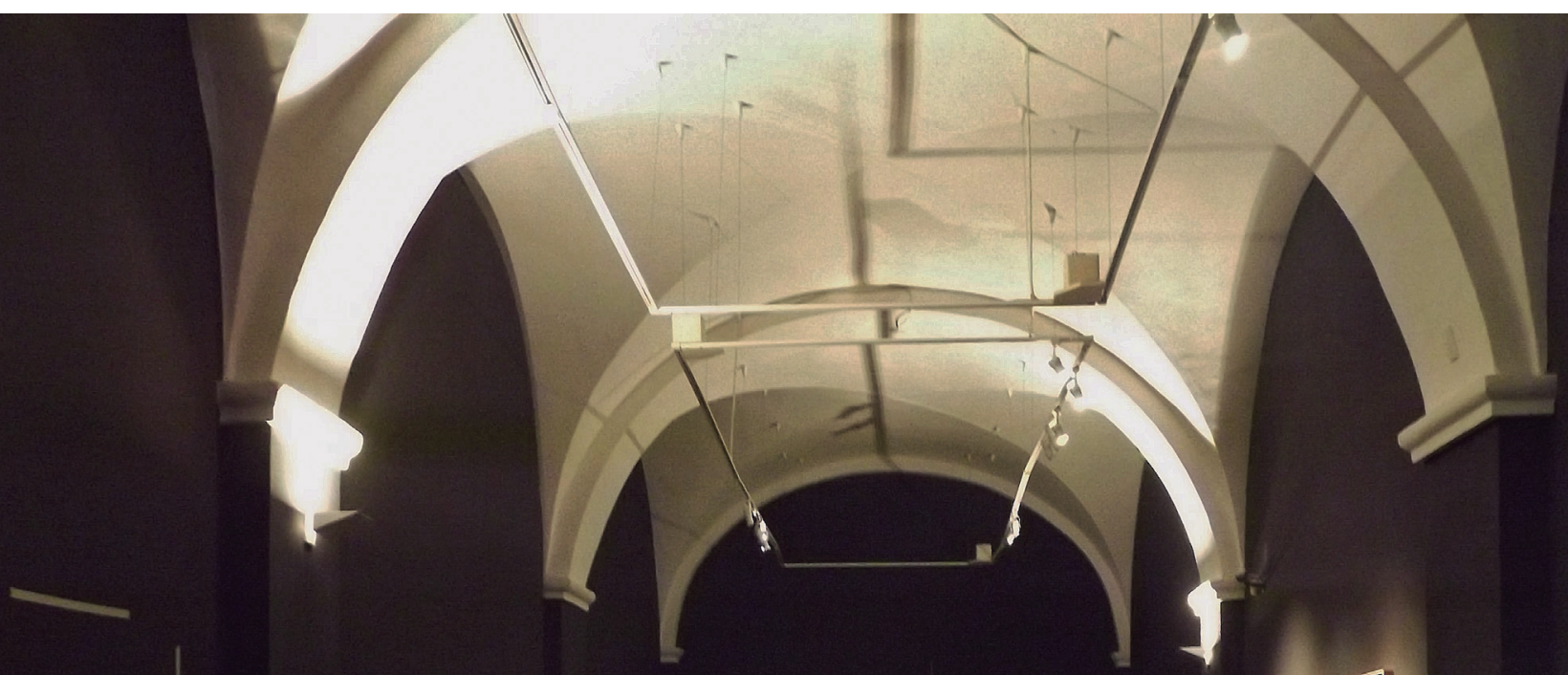

1
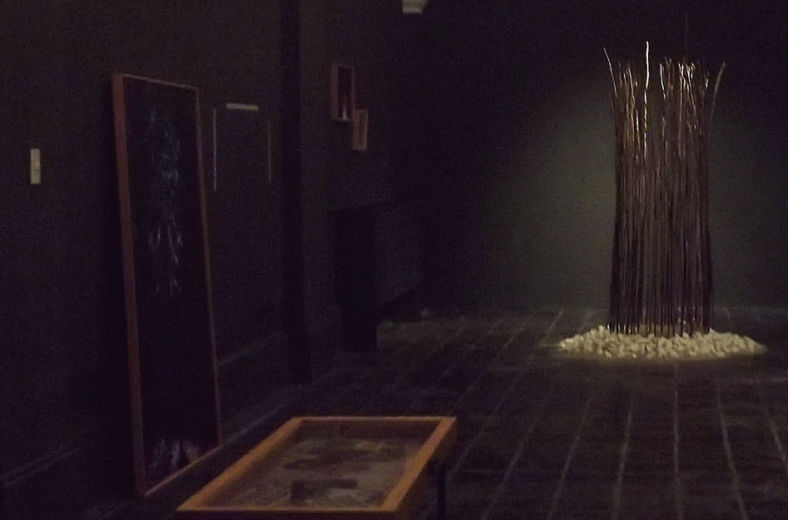

Figura 3 - Arte Pará 2013. 


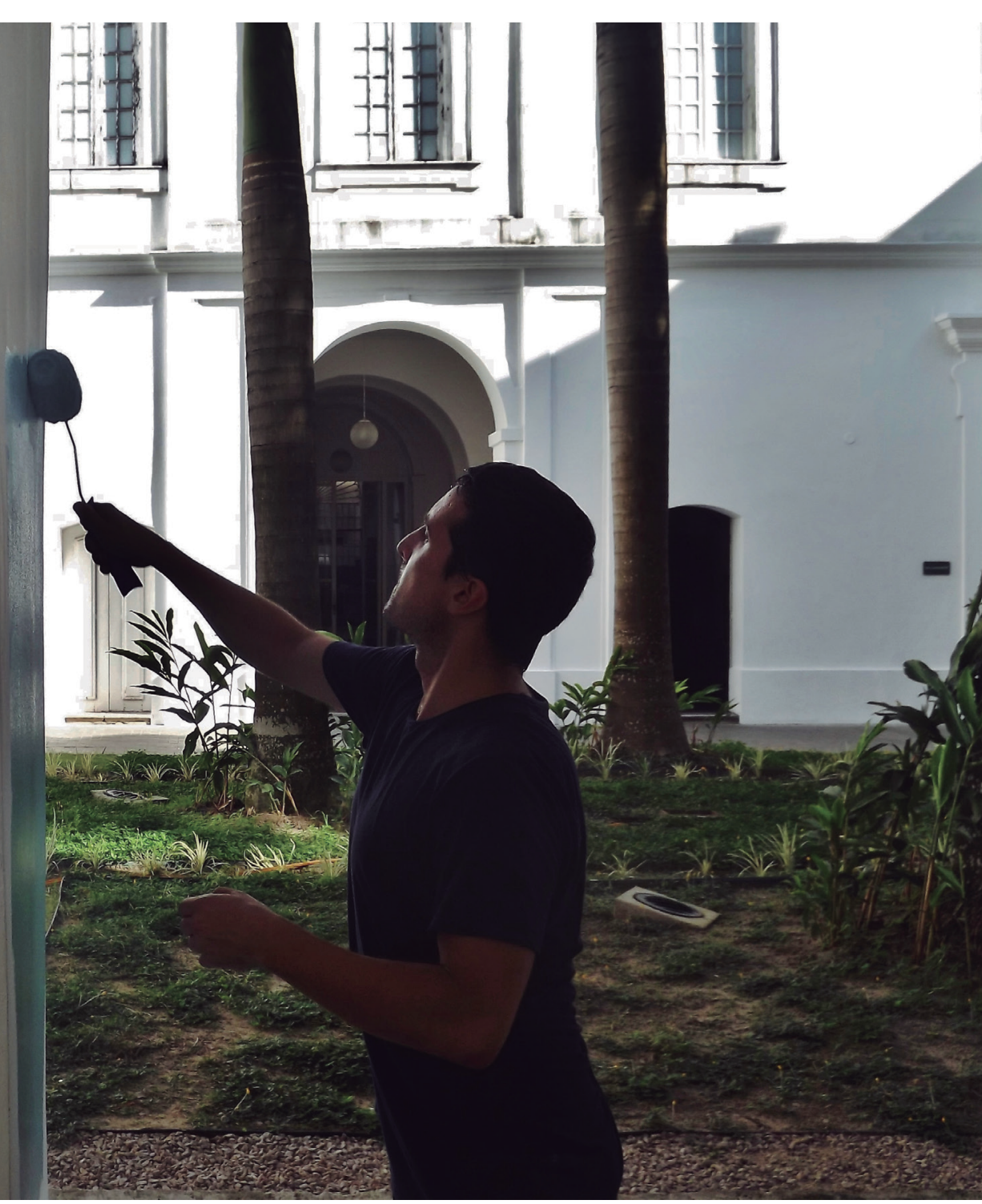

Figura 4 - Arte Pará 2013. 


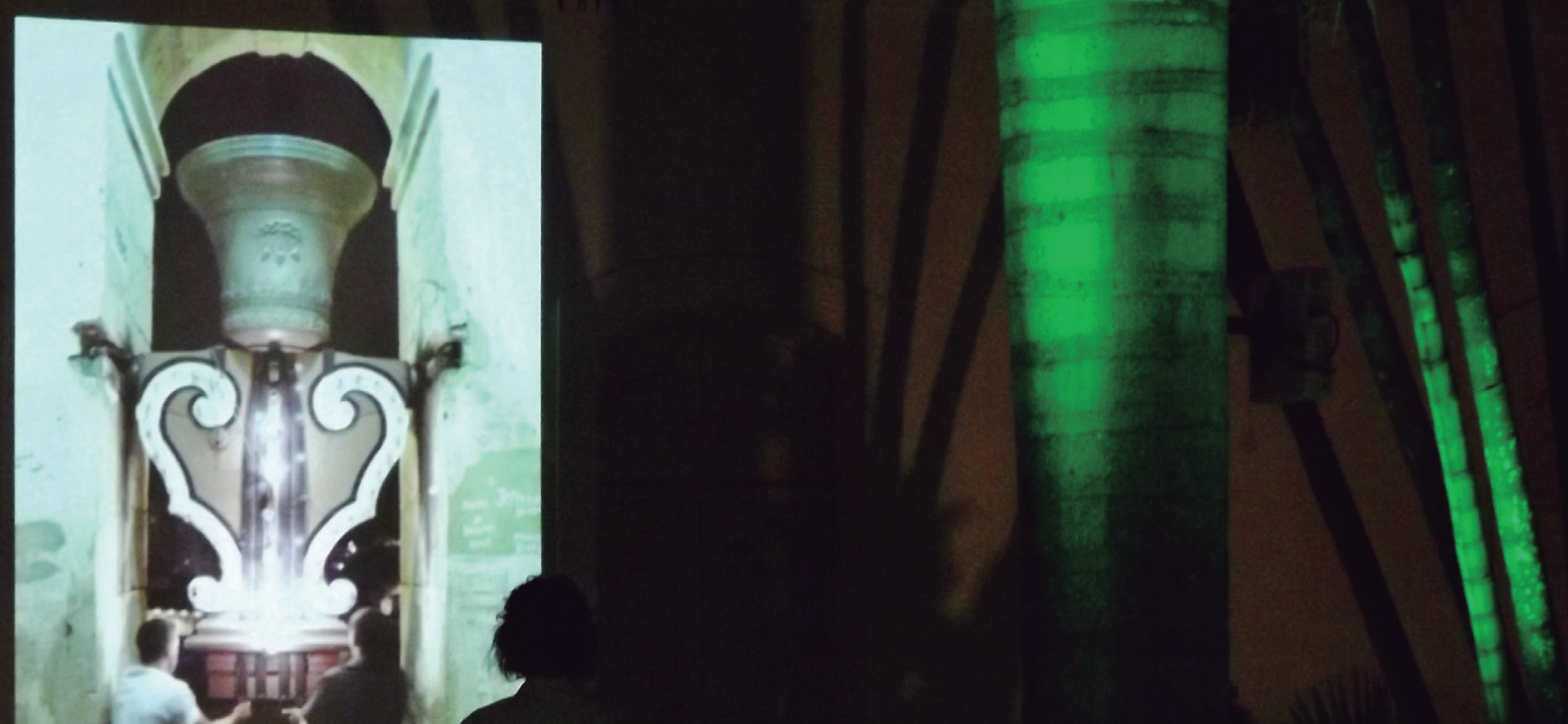

Figura 5 - Arte Pará 2013. 


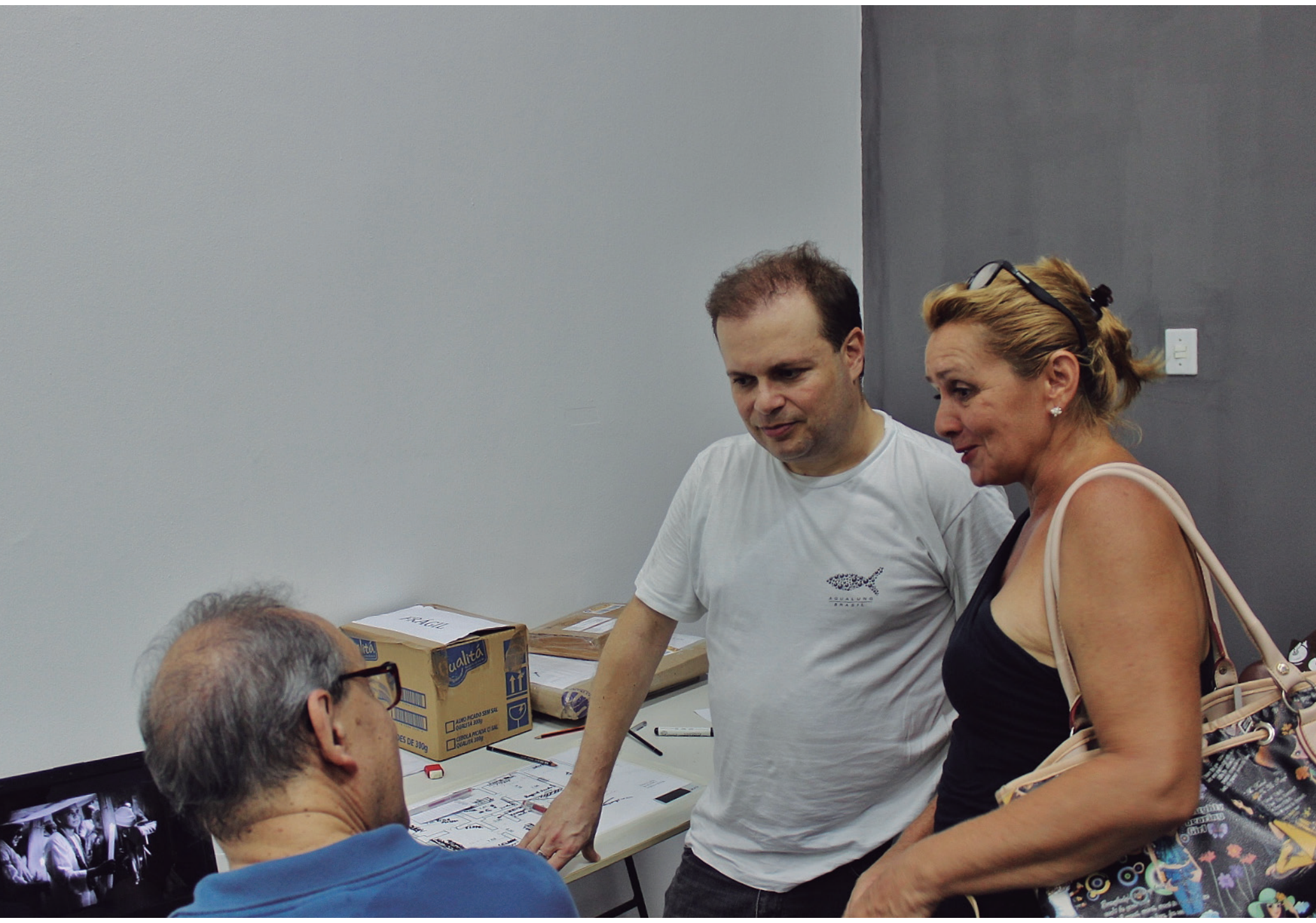

Figura 6 - Arte Pará 2014. 


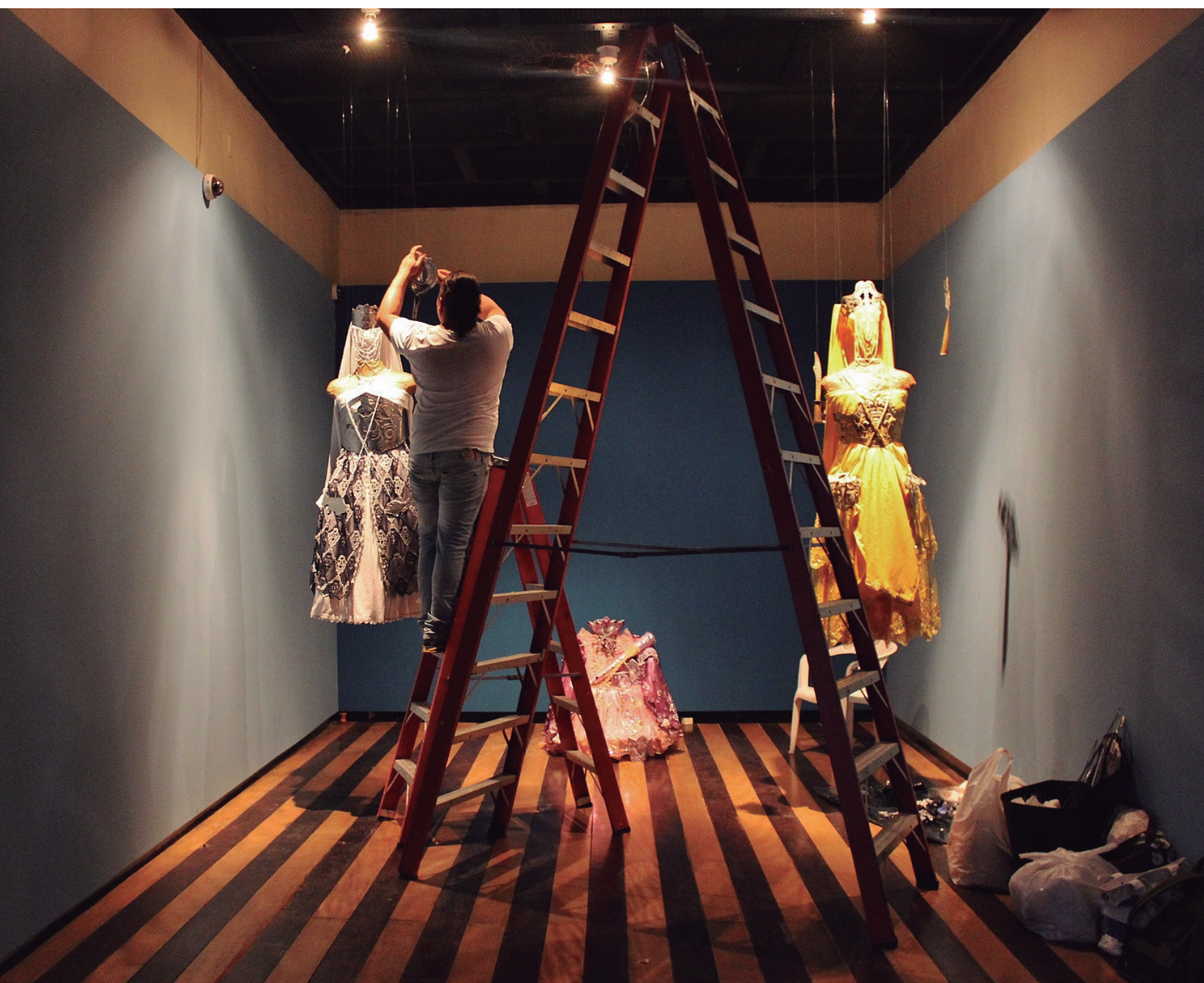

Figura 7 - Arte Pará 2014. 


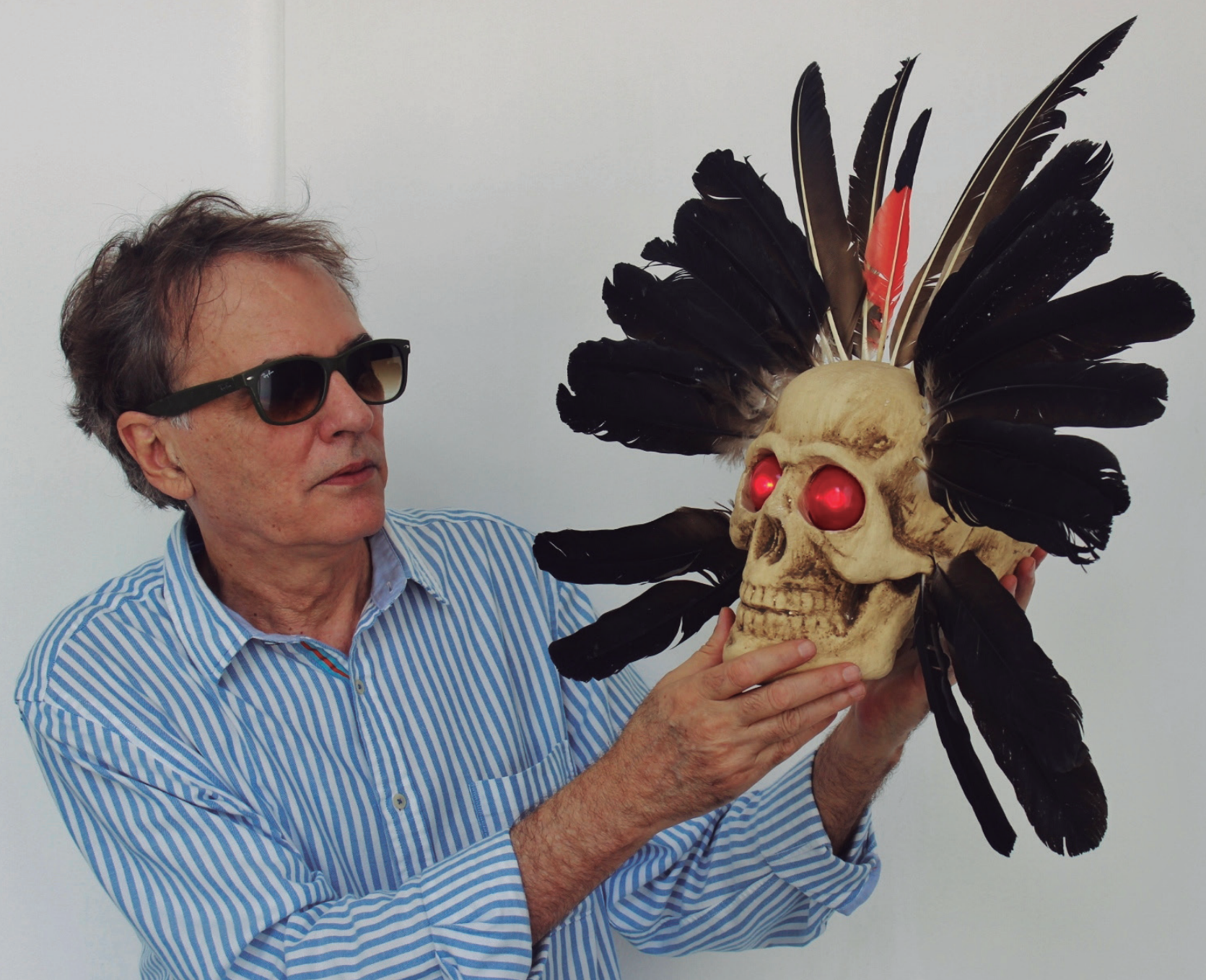

Figura 8 - Arte Pará 2015. 


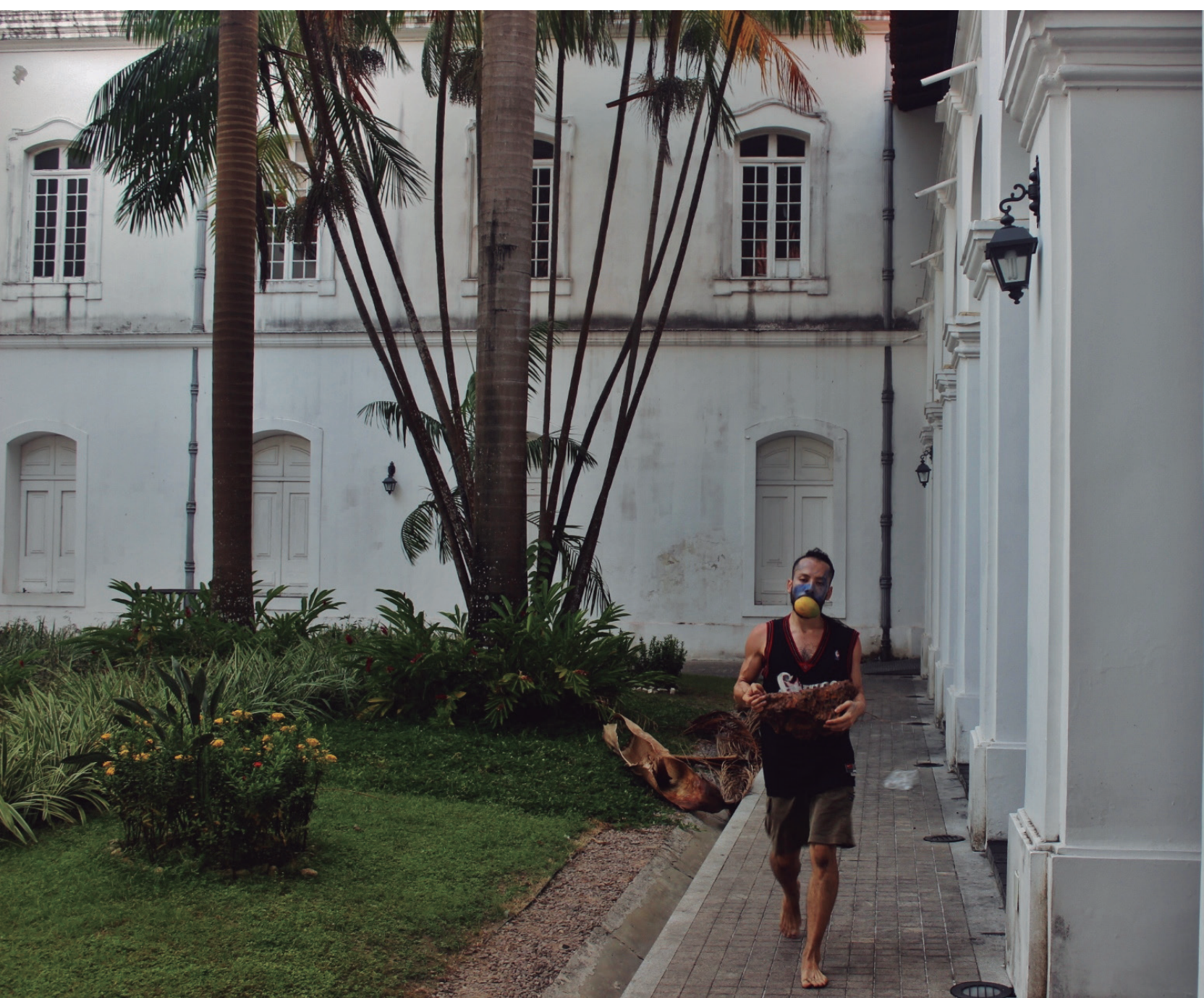

Figura 9 - Arte Pará 2015. 

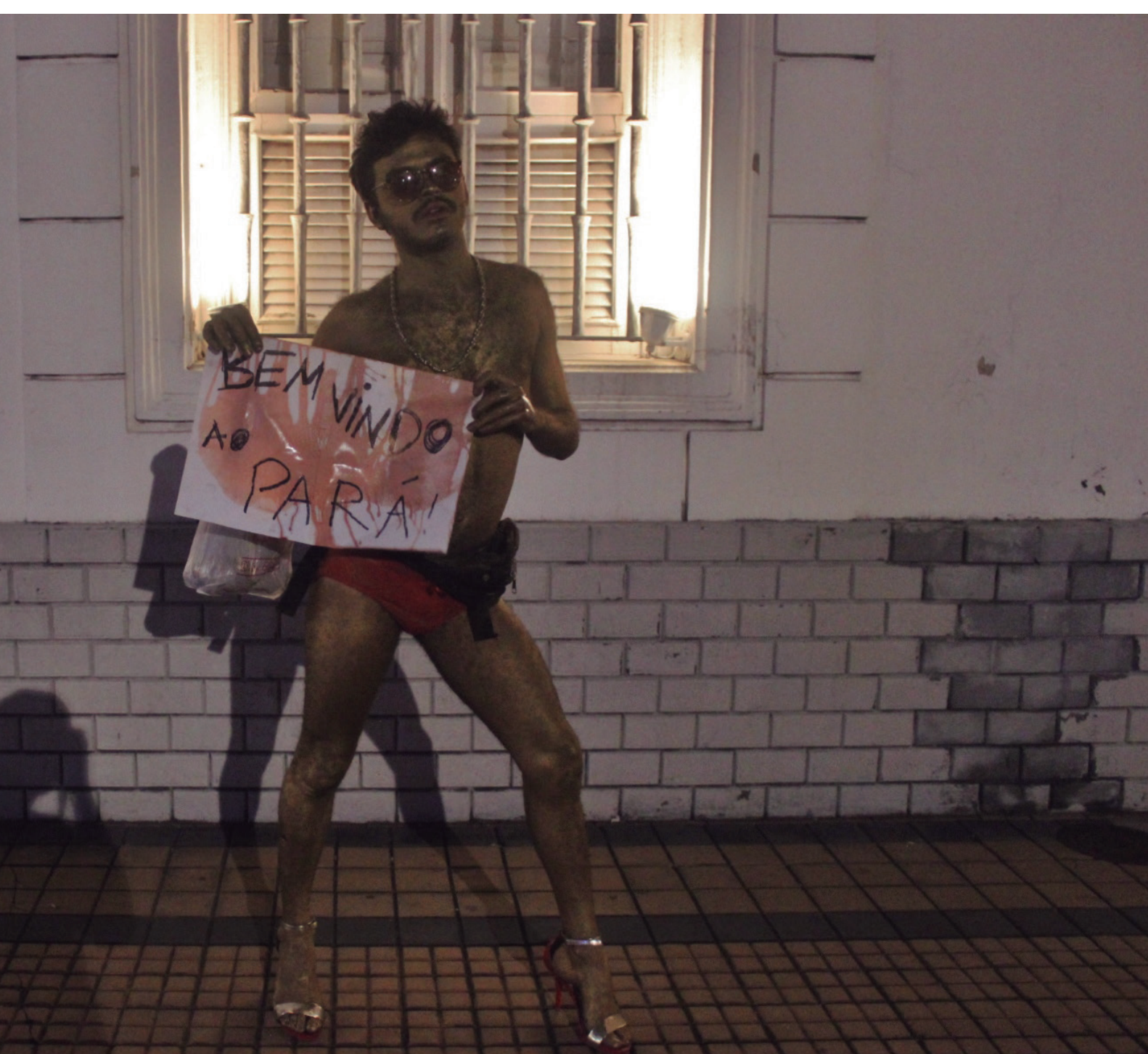

Figura 11 - Arte Pará 2015. 


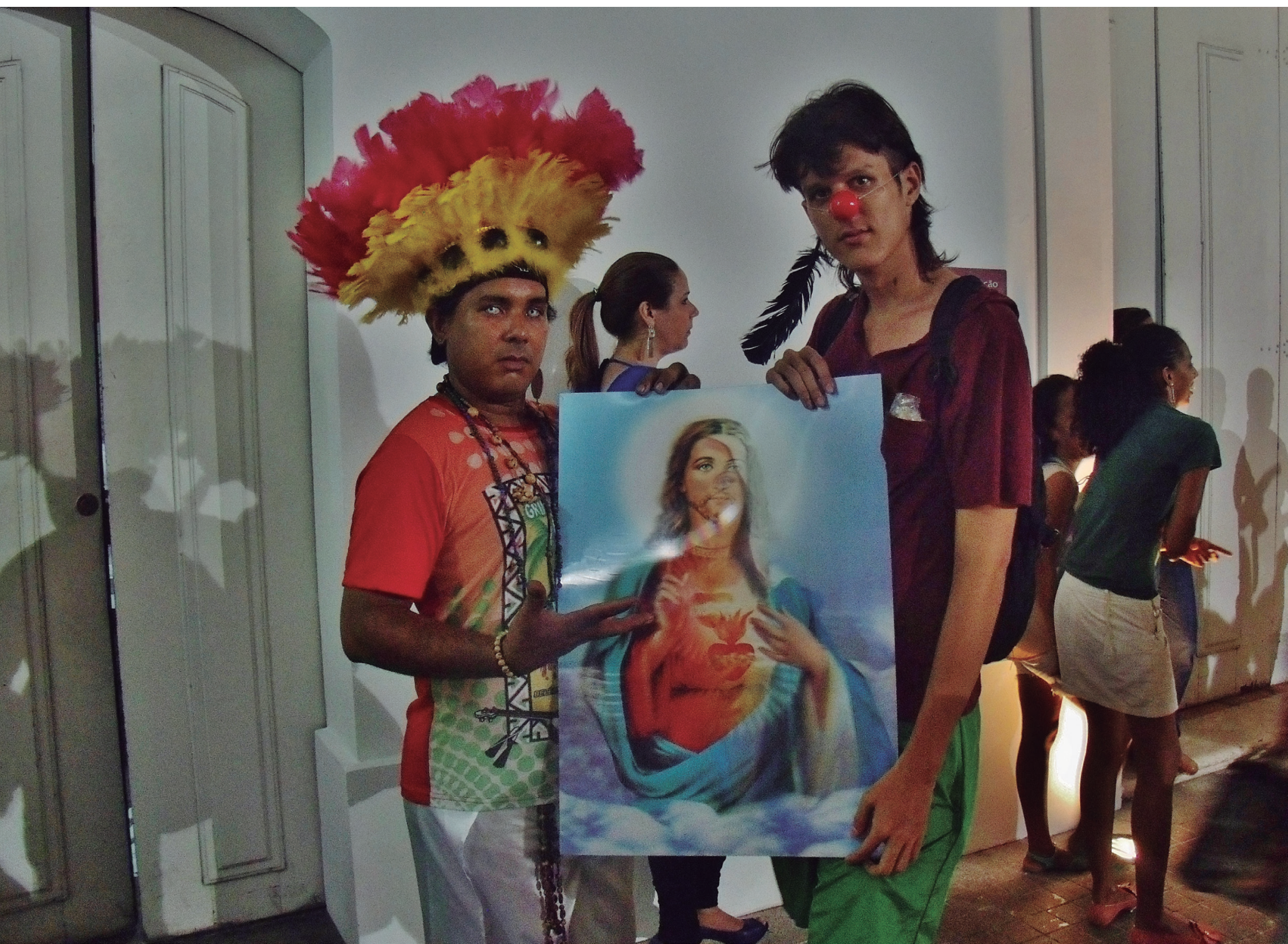

Figura 12 - Arte Pará 2012. 


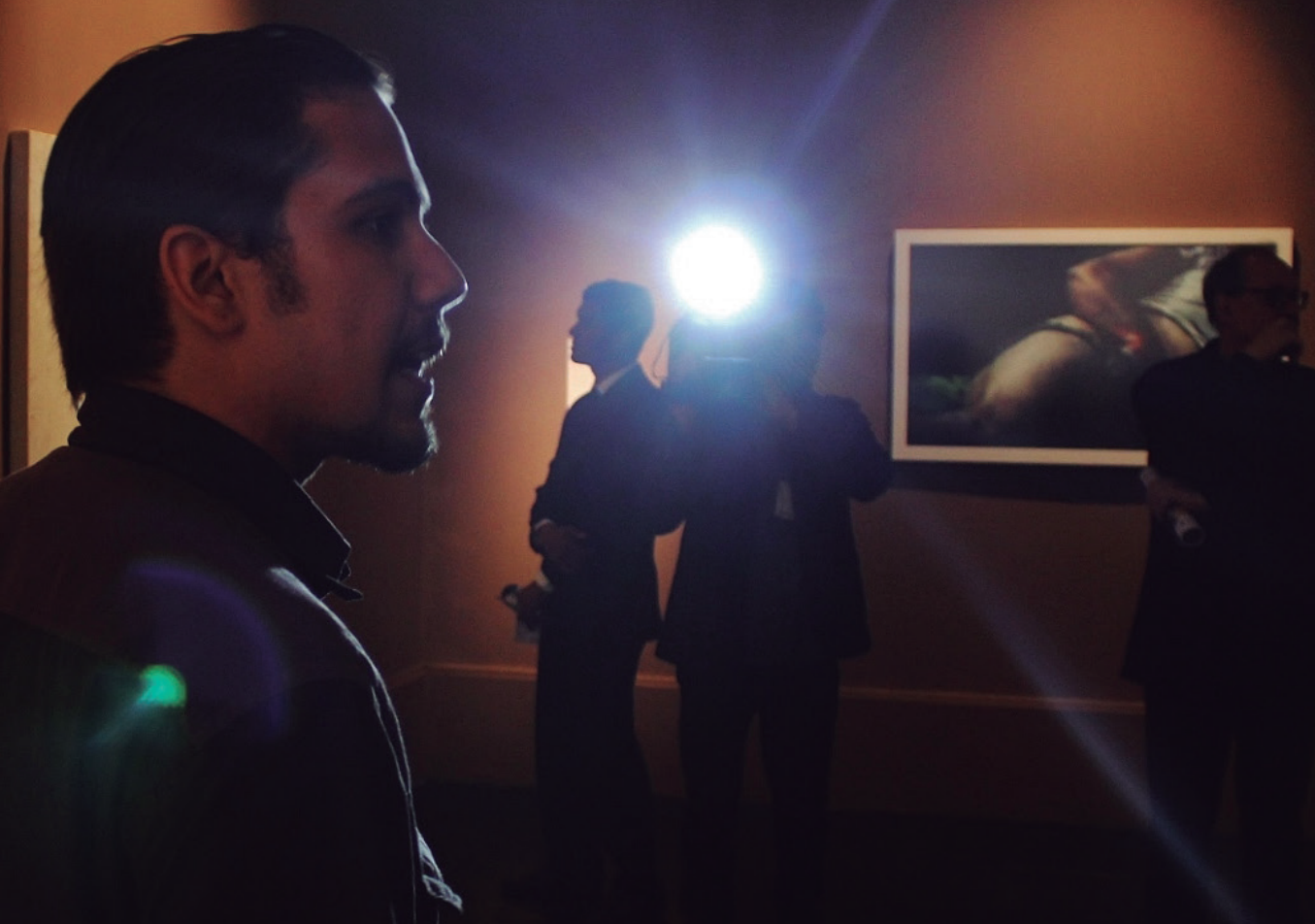

Figura 14 - Arte Pará 2014. 
$x^{3} x^{3} x^{x+2}$

\section{0}

7

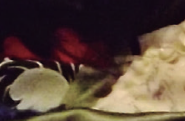

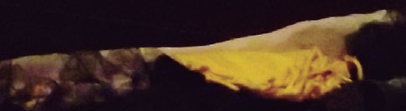

$\operatorname{lich}_{-\infty}$

-

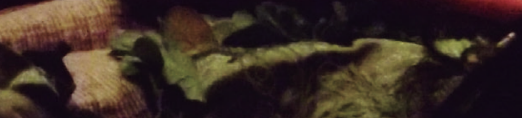

$-2 x^{2}$

$-2 \frac{5}{2}-$

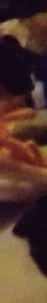
की 12

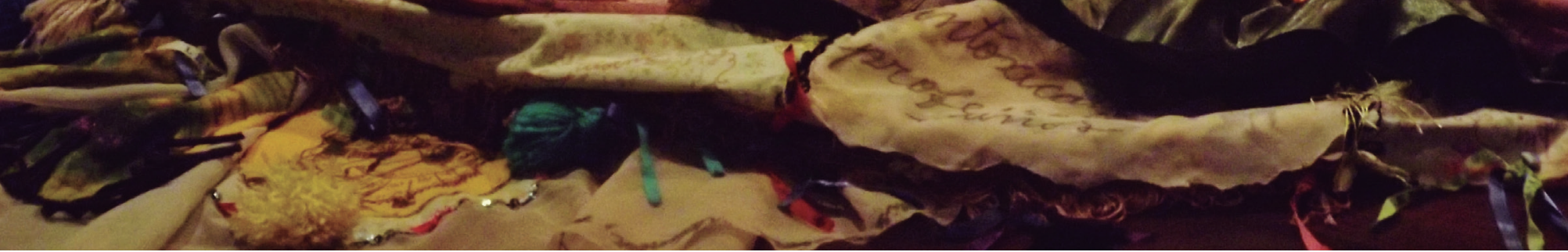

$\sqrt{2}$

$2 \cos 2$

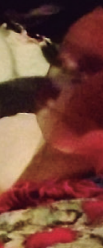

$-1,1$ के

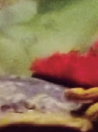

a $x^{2}+2$

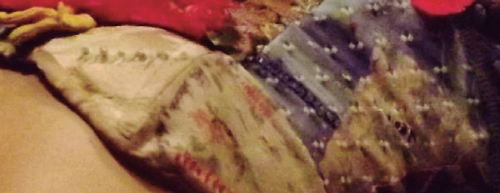
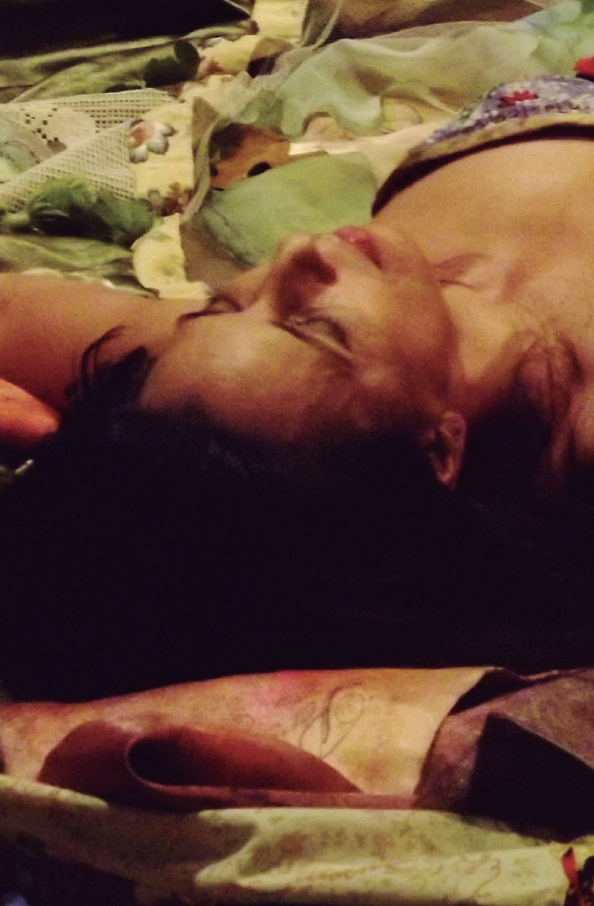

a.

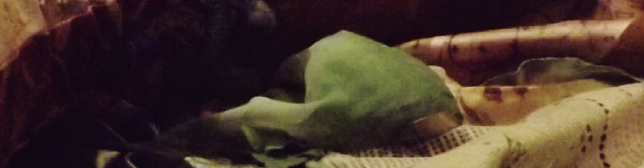

a)
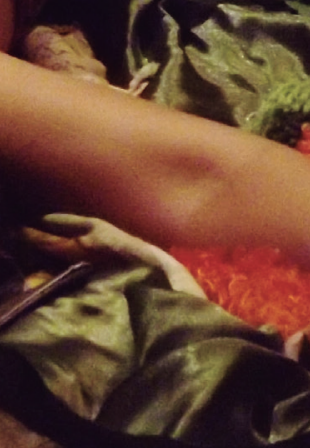

$\int_{1}^{2}$

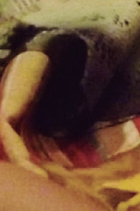

$3 \sqrt{60}$

Figura 15 - Arte Pará 2013. 